\title{
Cambio climático y café (Coffea arábica) en Acevedo, Huila: una lectura desde sus cultivadores
}

Climate change and coffee (Coffea arabica) in Acevedo, Huila: a reading from its growers

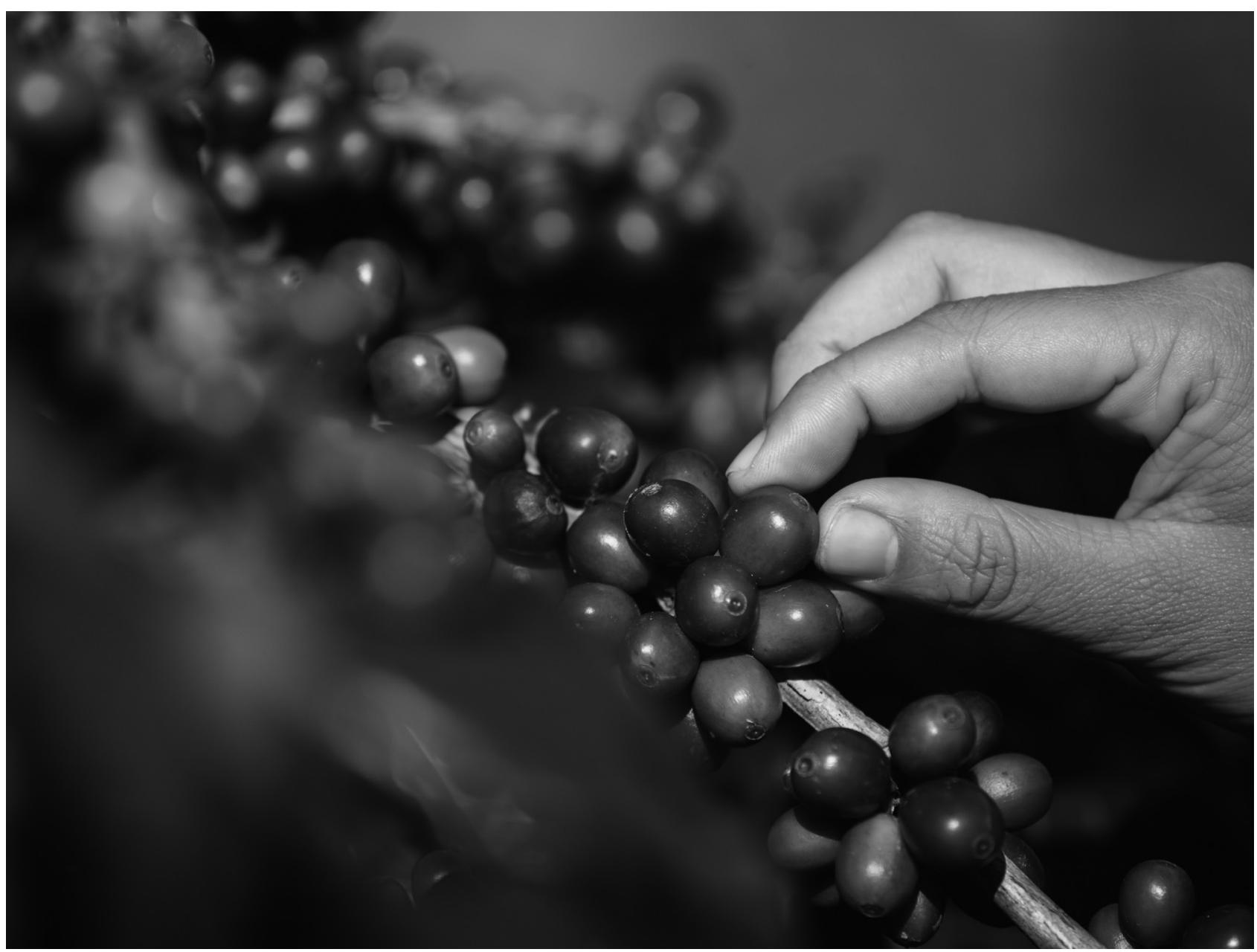




\title{
Cambio climático y café (Coffea arábica) en Acevedo, Huila: una lectura desde sus cultivadores ${ }^{1}$
}

\author{
Climate change and coffee (Coffea arabica) in Acevedo, \\ Huila: a reading from its growers
}

\author{
Verenice Sánchez Castillo, ${ }^{2}$ Yeisy Avendaño Pizo, ${ }^{3}$ Andrés Gaviria Astudillo, ${ }^{4}$ Carlos Gómez ${ }^{5}$
}

Artículo recibido en noviembre 27 de 2017; artículo aceptado en mayo 10 de 2018.

Este artículo puede compartirse bajo la Licencia Creative Commons Atribución-No Comercial-Compartir lgual 2.0 Genérica y se referencia usando el siguiente formato: Sánchez, V., Avendaño, Y., Gaviria, A. \& Gómez, C. (2018). Cambio climático y café (Coffea arábica) en Acevedo, Huila: una lectura desde sus cultivadores. I+D Revista de Investigaciones, 12 (2), 59-69.

DOI: https://doi.org/10.33304/revinv.v12n2-2018006

\begin{abstract}
Resumen
Se considera que los cambios drásticos del clima que se han venido presentando a lo largo de los últimos años han perjudicado la agricultura en general; países como Colombia, que lidera la producción mundial de café, atraviesan una crisis en su producción, que se presume se debe a dichos cambios. Los productores de Acevedo, Huila, una de las principales zonas cafeteras, caracterizada por su café de alta calidad, afirman que se han visto seriamente afectados por la variabilidad climática, evidenciada en la baja de su producción y en la disminución de sus ingresos, razón por la cual requieren de un mecanismo que les permita a sus cafetales adaptarse al cambio climático. En respuesta, la Federación Nacional de Cafeteros y el Centro Nacional de Investigaciones del Café han lanzado una serie de estrategias de adaptación a estos cambios; sin embargo, los productores se muestran apáticos a dichas propuestas por considerarlas poco ajustables a su economía.
\end{abstract}

Palabras clave: café, economía, estrategia de adaptación, variabilidad climática.

1. Artículo de reflexión, de enfoque cualitativo, resultado de un proyecto de investigación culminado, perteneciente al área de Ingeniería, subárea de Ingeniería agroecológica, desarrollado en el Grupo de Investigación en Agroecología y Desarrollo Rural-Giader de la Universidad de la Amazonía (Colombia). Dirección: Calle 17 n.44-51, Florencia, Caquetá.

2. Miembro del Grupo de Investigación en Agroecología y Desarrollo Rural - Giader, Ingeniera en Agroecología, Magister en Ambiente y Desarrollo, doctoranda en Antropología, Universidad de la Amazonía (Colombia). ORCID ID: http://orcid.org/0000-0002-4472-6191 Correo electrónico: ve.sanchez@udla.edu.co.

3. Estudiante de Ingeniería Agroecológica. Universidad de la Amazonía (Colombia). ORCID ID: http://orcid.org/0000-0002-0289-9369. Correo electrónico: ye.avendano@udla.edu.co.

4. Estudiante de ingeniería Agroecológica. Universidad de la Amazonía (Colombia). ORCID ID: 0000-0002-8405-5193. Correo electrónico: an.gaviria@ udla.edu.co.

5. Miembro del Grupo de Estudio de Futuro en el Mundo Amazónico - GEMA, Contador Público, Administrador Público, Especialista en Pedagogía y en Gestión Pública. Maestrando en Ciencias de la Educación, Universidad de la Amazonía (Colombia). ORCID ID: http://orcid.org/0000-0003-0425-

7201 Correo electrónico: carlosgomez325@gmail.com. 


\begin{abstract}
The drastic climate changes that have been presented over the past few years, is considered that have harmed the agriculture in general; countries such as Colombia, who leads the world production of coffee, is experiencing a crisis in its production, what is presumed to be due to such changes. For the case of Acevedo Huila who represents one of the main coffee areas, characterized for its high quality coffee; the coffee growers consider that have been seriously affected by climate variability evidenced in the lower their production and consequently the decline in their income; reason whereby require a mechanism that allows their coffee plantations an adaptation to climate change; In this aspect, the National Federation of Coffee Growers of Colombia has launched a strategy of adaptation to these changes; however, producers reflect an apathy to this proposal as little adjustable to your economy.
\end{abstract}

Keywords: Affectations, coffee, economy, strategy of adaptation, climate variability.

\section{Introducción}

El cultivo de café (Coffea arábica L.) se ubica principalmente en los países tropicales de América Latina, Asia y África. Su grano es comercializado en los mercados internacionales, siendo el segundo producto de mayor demanda en el mercado mundial y solo superado por el petróleo (Centro de Estudios para el Desarrollo Rural Sustentable y la Soberanía Alimentaria [Cedrssa], 2014). Se estima que en el mundo se producen alrededor de 7,7 millones de toneladas de café por año, en una superficie de 10,5 millones de hectáreas en más de 50 países, siendo América Latina la mayor productora, con el $85 \%$ del total mundial, seguido por Asia, que aporta el $10 \%$ y África con el $5 \%$. En cuanto a países, Brasil es líder en producción, con 2,5 millones de toneladas por año, seguido por Vietnam, con 1,6 millones y en tercer lugar, Colombia con 810000 toneladas por año (Infocafé, 2015).

En Colombia, en el año 2013, se contaba con 936682 ha cultivadas y una producción que en los primeros cinco meses de ese año llegaba a los 4026000 sacos (Federación Nacional de Cafeteros de Colombia [Fedecafé], 2013a; 2013b). Para el periodo comprendido entre febrero de 2016 y enero de 2017, la cosecha cafetera alcanzó los 14,4 millones de sacos de $60 \mathrm{~kg}$, $1 \%$ más frente a los 14,2 millones producidos en el periodo anterior (Fedecafé, 2017). Sin embargo, pese a la importancia económica del cultivo para centenares de familias, los niveles de producción y los rendimientos en toneladas por hectárea año, se han visto afectados, entre otros factores, por la variabilidad climática, la cual influye no solo en la producción sino en la dinámica de la estructura del mercado mundial (Cedrssa, 2014).

Para Ortiz (2012), las alteraciones del clima han generado la disminución en los rendimientos de los cultivos y la calidad del grano producido; de igual forma, Zapata (2015) identificó que tanto la escasez como la baja calidad del agua, además de la variación en los ciclos climáticos anuales, no les permite a los cafeteros tener claridad en cuanto a las temporadas húmedas y secas para planear las labores del cultivo.

Al sur del país se encuentra el departamento del Huila, el cual, ante la imposibilidad de cultivar café por debajo de los 1200 metros sobre el nivel del mar, se convirtió en líder de la producción nacional. En esta región el café se cultiva en 35 de los 37 municipios, en un área de 139138 hectáreas, con una producción superior a los 800000 sacos al año (Café de Colombia, 2014b). Aunado a ello, son numerosos los títulos que los caficultores de esta región han obtenido en la competencia Tasa de la Excelencia, además de los atractivos precios que los extranjeros pagan por un café de alta calidad y los cafés especiales (Café de Colombia, 2014b).

El municipio de Acevedo también es representativo en este escenario cafetero, con un aproximado de 9054 hectáreas cultivadas en café y más de 2000 familias vinculadas al sector. Este hecho hace que además de ofrecer un producto de calidad, la actividad cafetera sea una importante fuente de empleo en la zona, pues demanda mano de obra tanto familiar como contratada (Alcaldía Municipal, 2012 a). Sin embargo, al igual que en el resto del país, la variabilidad climática, caracterizada por amplios periodos de sequía seguidos o antecedidos por fuertes precipitaciones en épocas no esperadas, ha producido alteraciones en el proceso fenológico de este cultivo (Charlotte, Jarvis \& Ramírez, 2011). El fenómeno de La Niña ha generado el clima propicio para la aparición de nuevas plagas y enfermedades, mientras que la permanencia de las lluvias ha impedido la adecuada floración de los cafetos (Cano et al., 2012).

Por su parte, el fenómeno de El Niño, caracterizado por la ausencia de lluvias, ha traído como consecuencia una alta presencia de granos de café de baja densidad. En este orden, los daños en la cosecha dependen del déficit hídrico que se tenga durante la floración y la etapa de llenado de los granos, lo cual se considera crítico para la formación del fruto (Centro Nacional de Investigaciones 
de Café [Cenicafé], 2009; Café de Colombia, 2014a; Portafolio, 2015a).

Ante este fenómeno, la Federación Nacional de Cafeteros de Colombia [FNC] y el Centro Nacional de Investigaciones de Café [Cenicafé] han generado una serie de alternativas para que las familias caficultoras puedan adaptar sus cafetales al cambio climático; sin embargo, se desconoce si estas estrategias han sido recibidas, ensayadas y adoptadas por los productores. Tampoco se tiene claridades acerca de la posición de los productores al respecto y las acciones emprendidas desde lo local como respuesta al fenómeno global (FNC, 2009).

Por lo anterior es necesario caracterizar la percepción de los caficultores frente a las afectaciones ocasionadas en sus cafetales por la variación del clima, además de los cambios que han tenido que realizar para adaptarse al cambio y si esto se ha hecho de manera empírica o corresponde al conocimiento y aplicación de la estrategia propuesta por la FNC. Con los insumos generados en la presente investigación se pretende avanzar en la construcción de unos lineamientos para consolidar una estrategia local que les permita a los caficultores adaptarse mejor al cambio climático.

\section{Método}

\section{Localización y contexto}

El departamento del Huila está localizado al suroccidente del país, entre los 3055'12" y 1030'04" de latitud norte, y los $74^{\circ} 25^{\prime} 24^{\prime \prime}$ y $76^{\circ} 35^{\prime} 16^{\prime \prime}$ de longitud al oeste del meridiano de Greenwich (Gobernación del Huila, 2015a). El presente estudio se llevó a cabo en la vereda El Carmen, del municipio de Acevedo, ubicada a $1^{\circ} 48^{\prime} 09.49^{\prime \prime} \mathrm{N}$ y $75^{\circ} 56^{\prime} 13.13^{\prime \prime} \mathrm{O}$, aproximadamente a veinte minutos del casco urbano, el cual se encuentra localizado hacia el suroriente de este departamento; tiene 19914 habitantes (Gobernación del Huila, 2015b), cuenta con una extensión de $612 \mathrm{~km} 2$, el uso del suelo agrícola es del $42,64 \%$, equivalente a 26,044 ha. En esta zona del país la principal actividad productiva es el cultivo de café, con más de 16800 hectáreas plantadas (Alcaldía Municipal de Acevedo, 2012b).

\section{Enfoque metodológico}

La presente investigación se fundamenta en un paradigma crítico social, debido a que este enfoque permite comprender las interrelaciones de actores y su interacción con el medio social, político y ambiental, teniendo en cuenta la subjetividad como condición imposible de superar en la investigación y sus actores investigadores e investigados (Gutiérrez, 2014). El tipo de artículo es de reflexión, toda vez que a partir de fuentes de primera y segunda mano los autores y los actores involucrados ponen sobre la mesa sus puntos de vista sobre el tema en particular, en este caso, la variabilidad climática y sus efectos sobre el cultivo del café y los mecanismos locales de adaptación a esta.

\section{El método}

\section{Análisis de los posibles efectos del cambio climático sobre el cultivo del café.}

Para esta aproximación, la investigación se apoyó en la técnica arqueo de archivo, mediante la cual se consultaron diferentes bases de datos, periódicos, boletines locales y páginas web, para rastrear información que diera cuenta de las afectaciones del cambio climático en la producción de café. Así las cosas, las variables de estudio que se tuvieron en cuenta fueron: lugares, condiciones climáticas, afectaciones y resultados.

\section{Imaginario de los caficultores alrededor del cambio climático, la afectación en sus cultivos y sus mecanismos de adaptación.}

Identificación de actores clave. Para la selección de los actores clave se establecieron como criterios: que el productor fuese antiguo en la zona, que tuviera experiencia en la producción de café y que a su juicio se hubiera visto afectado por la variabilidad climática.

Aplicación de entrevistas: Una vez realizada la identificación de actores clave y establecido el contacto con ellos, se procedió a la realización de una entrevista a profundidad, cuyas variables de estudio fueron: cambio climático, producción y acciones realizadas para superar la crisis del cambio climático. La entrevista, previa autorización de los entrevistados, fue grabada, transcrita y puesta en un texto plano. Posteriormente, con ayuda del software de procesamiento para datos cualitativos Atlas Ti, se seleccionaron las frases de interés, a las cuales se les asignó un código de identificación o categorías; tras obtener el total de categorías, se procedió a clasificarlas en grupos de similitud, y una vez conformados los grupos, se les designó como familias de análisis. Posteriormente, se establecieron las relaciones de mayor importancia entre los códigos de cada familia, se realizó el respectivo dibujo de la red o networks, que fueron pieza clave para la redacción de los hallazgos y la triangulación de la información.

\section{Caracterización de las estrategias de adaptación al cambio climático de la Federación y Cenicafé y su adopción en el municipio de Acevedo. Para esta aproximación se combinaron herramientas de}


primera y segunda mano. En primer lugar se dialogó de manera informal con los cultivadores de café a fin de indagar acerca de sus mecanismos de adaptación al cambio climático. En segunda instancia se revisaron las estrategias planteadas por la FNC y Cenicafé para la adaptación al cambio climático. Posteriormente, se hizo una triangulación para establecer si las medidas adoptadas por los productores tenían estrecha relación con la estrategia nacional o eran mecanismos locales; de esta manera se procedió a la redacción de los hallazgos.

\section{Resultados}

\section{Análisis del impacto del cambio climático en el cultivo del café}

Laderach et al. (2009) señalaron que el cambio climático afectaría en forma notoria la producción de café en América Central, tanto que ciertas zonas dejarían de producir este cultivo, y quienes lo produjeran se verían obligados a sustituirlo por otros cultivos o incluso a migrar hacia otros lugares. También sostuvieron que los productores de otras zonas deberían buscar estrategias para adaptar el cultivo a nuevas formas de gestión. Para Camargo (2010), la variación de la producción media anual de café está relacionada con la variabilidad climática, debido a que los factores climáticos afectan el desarrollo de las fases fenológicas del cultivo. En línea con lo anterior, Patiño, Pencue y Vargas (2016) señalan que el contenido de humedad en el grano de café seco debe ser el adecuado -alrededor del 11\%-, de lo contrario, su calidad se deteriora; por su parte, Cuadras (2015) explica que el incremento de la temperatura acelera el proceso de maduración del grano, lo que conlleva la pérdida de calidad. Según Ortiz (2012), las afectaciones del clima sobre el café en la zona de Mesoamérica, donde las temperaturas han aumentado entre 0,2 y $1^{\circ} \mathrm{C}$ y las precipitaciones han disminuido en un $15 \%$ durante las últimas tres décadas. Este mismo autor advirtió, en ese mismo año, que las condiciones óptimas para la producción de café de alta calidad, como el arábigo ácido, se verían afectadas por las oleadas de calor, lo cual también favorecería el desarrollo de plagas como la roya del café. A su turno, la Coordinación Latinoamericana y del Caribe de Pequeños Productores de Comercio Justo [CLAC] (2015), indica que la caficultura se ha visto afectada por los cambios en el clima y la aparición y proliferación de plagas y enfermedades, como la roya, la broca, la araña roja, entre otras, siendo la roya la más conocida y de mayor impacto en el cultivo.

Ortiz (2012) indica que el ciclo del cultivo del café depende del régimen de precipitaciones, dado que las primeras lluvias dan origen a la floración; posteriormente, cuando las precipitaciones son bajas o elevadas, el cafeto florece y los frutos caen de los árboles, lo que reduce la calidad del café y disminuye los precios de mercado. En el caso particular del fenómeno de La Niña, representado por precipitaciones elevadas, la producción disminuye. Evidencia de ello la ofrece Cuadras (2015), según el cual las lluvias torrenciales que se registraron en las principales zonas productoras en el año 2011 han tenido como consecuencia la menor cosecha de café de los últimos treinta años.

\section{Imaginario de los caficultores alrededor del cambio climático y la afectación en sus cultivos}

Familia productividad. Los largos periodos de verano, con altas temperaturas contrastadas con las repentinas $y$ a veces extendidas lluvias, hacen que los porcentajes de humedad en el clima sean más altos, lo que genera un ambiente propicio para el surgimiento de plagas y enfermedades $y$, en especial, causadas por hongos y virus. Para los cultivadores de café, estas situaciones se han vuelto más reiterativas en los últimos años por los efectos la variabilidad climática, la cual, según el Grupo Intergubernamental de Expertos sobre el Cambio Climático [IPCC] (2007), involucra las variaciones del estado medio del clima y otras características estadísticas de este. En este orden, la variabilidad puede deberse tanto a procesos internos naturales del sistema climático como a variables del forzamiento externo natural.

Para el CLAC (2015), el cambio climático ha traído consecuencias negativas sobre la producción de café, en tanto algunas plagas y enfermedades que antes no estaban tan desarrolladas ahora sí lo están y además han cambiado su comportamiento, volviéndose resistentes a condiciones adversas.

Para Jaramillo y Arcila (2009), el problema de las plagas y las enfermedades radica en el exceso de humedad en el suelo y en el ambiente, muy propio de los largos periodos de lluvia, los cuales favorecen la presencia de enfermedades como el mal rosado (Erithricium salmonicolor), la roya del café (Heileia vastatrix), así como del incremento en la ocurrencia de llagas radicales y daños de tallos en plantas jóvenes causados por diferentes tipos de anélidos. De igual forma, los largos periodos de sequía incrementan la caída de frutos al suelo, los cuales se convierten en el nicho perfecto para el surgimiento de la broca (Corporación Colombiana de Investigación Agropecuaria [Corpoica], 2011).

Cabe recordar que la roya es una enfermedad ocasionada por el hongo Hemileia vastatrix, la cual afecta directamente a las hojas maduras del cafeto; sin 
embargo, en estado severo también afecta a las jóvenes (Asociación Nacional de Café [Anacafé], 2013). Sobre esta situación los cafeteros afirman que anteriormente era un asunto manejable, pues los niveles de presencia de la enfermedad eran bajos y singulares, mientras que en la actualidad las intensas lluvias hacen que haya más humedad y mayor proliferación del hongo, por tanto, mayor caída de hoja con ataque no selectivo, sino a toda la superficie foliar del arbusto, lo que ocasiona bastantes pérdidas en la producción.

Barquero (2013) plantea que la roya se puede manejar empleando variedades resistentes, y adoptando nuevas prácticas culturales como mayores distancias de siembra, poda de cafetos, manejo de la sombra y combate químico mediante el uso de fungicidas. En el caso de estudio los lugareños han incorporado a sus cultivares variedades resistentes para el caso de la roya; sin embargo, a su juicio, estas no producen igual que las otras.

En el caso de las plagas, los entrevistados coincidieron que con la variabilidad y el cambio climático la broca del café, Hypothenemus hampei Ferrari, ha sido la plaga más perjudicial para la caficultura, en razón a que coloniza los frutos durante su maduración y destruye una gran parte de la cosecha en un tiempo corto. De acuerdo con Barquero (2013), el control se debe realizar mediante un programa de manejo integrado que comprende varias tácticas y opciones de control, como son control cultural, control biológico, control etológico o trampeo y control químico (Dufour, 2008). Los entrevistados aseguraron que han optado por combatir la broca especialmente a través del soqueo de los cafetales, práctica que para los productores es un volver a empezar, pues este método de control implica cortar todos los arbustos para eliminar con ellos la enfermedad. Luego, el café debe retoñar, es decir, prácticamente debe volver a nacer, algo que se considera bastante demorado y afecta el tiempo de producción, desencadenando incertidumbre en el productor.

Por otro lado, como una medida de preparación del cultivo ante la presencia de enfermedades, especialmente fungosas causadas por la humedad, los productores han optado por incrementar los niveles de fertilización, ya que, según su imaginario, esto permite que el cultivo resista cualquier enfermedad y asegura la producción. Esta situación, a su vez, desencadena altos costos de producción, esclavitud por parte de los finqueros y dependencia de la tierra a los agroquímicos para poder producir (Figura 1).

Familia tecnología. Los problemas ambientales, específicamente los cambios de clima que afectan el cultivo del café, deben ser manejados y adaptados, retomando tanto el conocimiento local como las nuevas tecnologías. En este sentido, la asistencia técnica sugiere controles reiterativos tanto químicos como manuales para lograr una producción óptima y de excelente calidad; sin embargo, la adopción de lo que se transfiere depende tanto de la funcionalidad de la técnica como de los resultados en la práctica, que permitan que la recomendación sea replicable evitando así la proliferación de nuevos focos de infestación de la plaga o la enfermedad en las veredas y predios vecinos (Figura 2). Esta percepción de los cultivadores de café acerca de que la aplicación sucesiva de agroquímicos genera alta dependencia y mayores costos que no son compensados con los niveles de producción media por hectárea, coincide con lo encontrado por Sánchez, Rincón, Toledo y Gómez (2016) en su trabajo con cultivadores de maracuyá (Pasiflora edulis). Estos investigadores consideran que la transferencia de tecnología es un proceso de extensión con actividades interconectadas que producen un resultado relacionado con la adopción de una innovación tecnológica, la adquisición de conocimientos para solucionar problemas o el fortalecimiento de la interconexión organizacional. De acuerdo con Calivá (2013), se precisa de la concurrencia de una política nacional pero complementada por la política local tanto en investigación como en extensión, y los comités departamentales de caficultores son los llamados a definir las prioridades. Sin embargo, a juicio de Ramírez (2014), el servicio de extensión no está haciendo el trabajo como se debería, pues este debería ser descentralizado y reforzado, y trasmitirse de manera más frecuente, con permanente acompañamiento (Ariza, 2015).

En consonancia con lo planteado por los autores, todos los tipos de control en cualquiera de las plagas $y$ enfermedades deben ser complementarios y no únicos, y hacia eso es que se deben dirigir los esfuerzos del acompañamiento técnico, pues la variabilidad y la inestabilidad del clima tiende a ser más agresiva cada día y esto favorece los problemas agronómicos en los cultivos, y, por tanto, los rendimientos y utilidades de estos. En resumen, la combinación de control cultural (Catalán, 2012), control químico (Cermeli, 2016), y control orgánico es la base para hacer frente a los diferentes embates de la variabilidad.

Familia socioeconómica. Las afectaciones de los cultivos de café como consecuencia de los cambios del clima han generado una problemática tanto para el productor como para la vecindad, en tanto que la cosecha y la calidad del café disminuyen, convirtiéndose en un factor de preocupación dado que los ingresos de las familias bajan y no logran suplir sus necesidades de producción. Esto se debe, en parte, a que la información de alertas acerca del clima es poco accesible para los productores y también es incierta, hecho que los deja en un estado 
de incertidumbre con respecto a las temporadas Iluviosas o secas. En caso de que hubiera una certeza al respecto, habría una mayor responsabilidad por parte del caficultor en la toma de acciones para salvaguardar su producción y tendrían la esperanza de que podrán mantener una estabilidad económica (Figura 3). Como se ha expuesto, el sector cafetero es de los más afectados por el cambio climático; esta situación, sumada a la caída de los precios, ha generado más vulnerabilidad para los pequeños productores, quienes para superar la crisis productiva terminan endeudándose para acceder a agroquímicos y así atender las emergencias en el manejo de plagas y enfermedades y los procesos de fertilización, por lo cual se generan mayores costos de producción y, por ende, menores ingresos por ventas del grano. Esta situación ha hecho que este renglón de la economía sea cada vez menos rentable y se incrementen los círculos de la pobreza rural (CLAC, 2010).

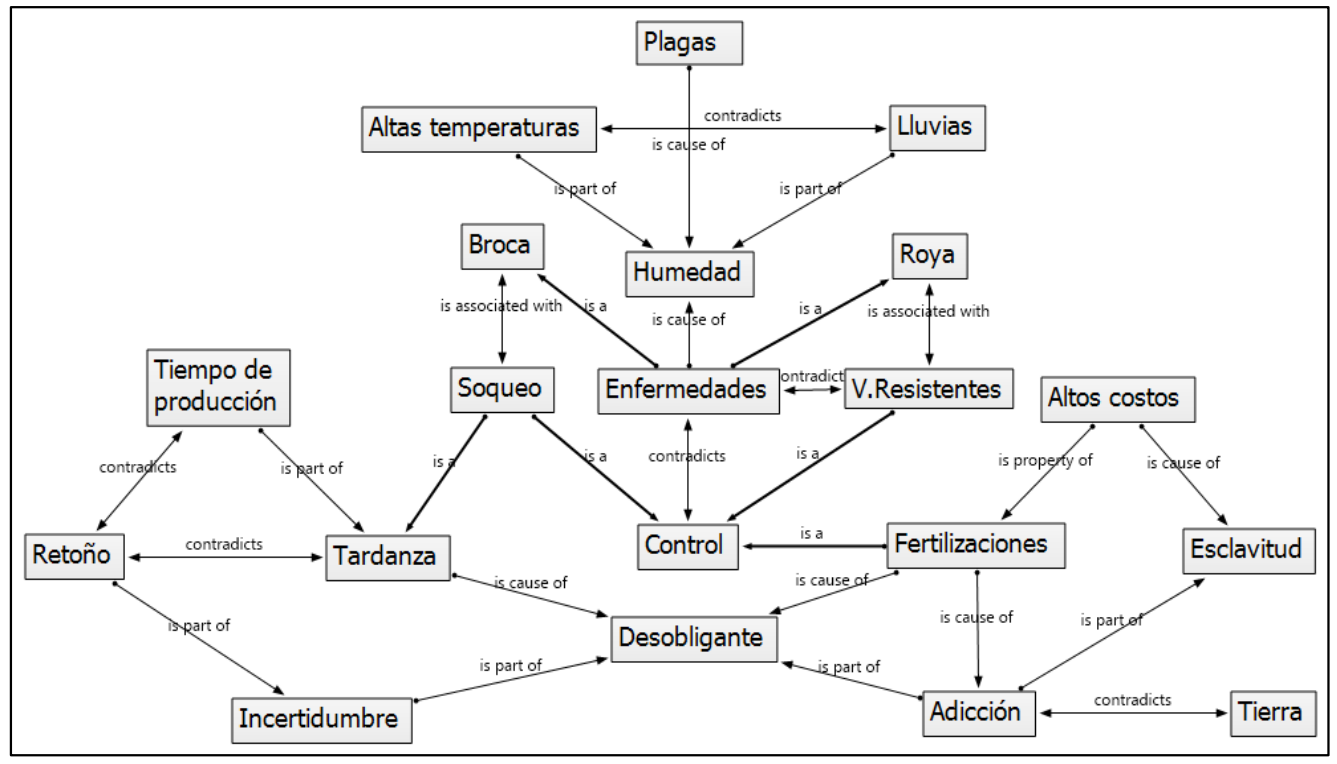

Figura 1. Productividad. Fuentes: Autores

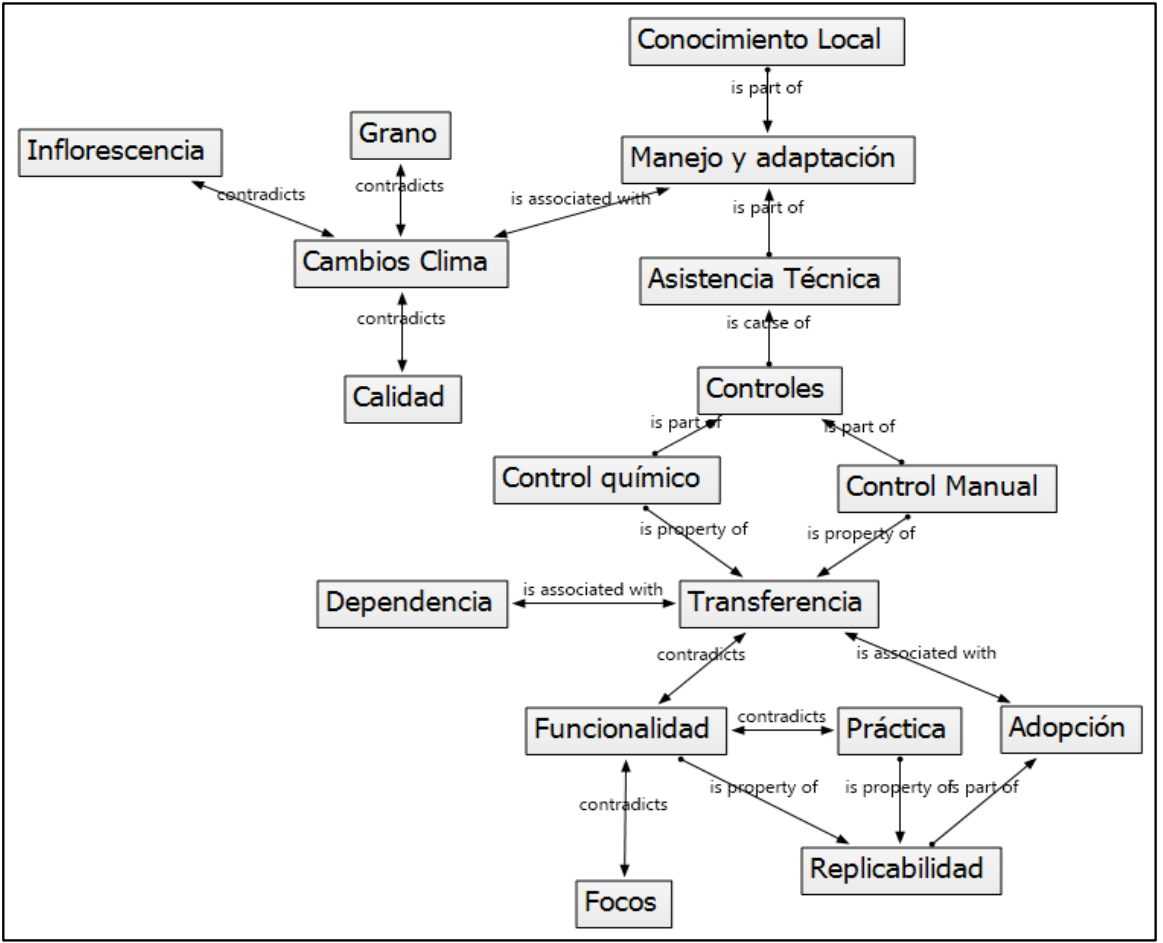

Figura 2. Familia tecnología. Fuentes: Autores 


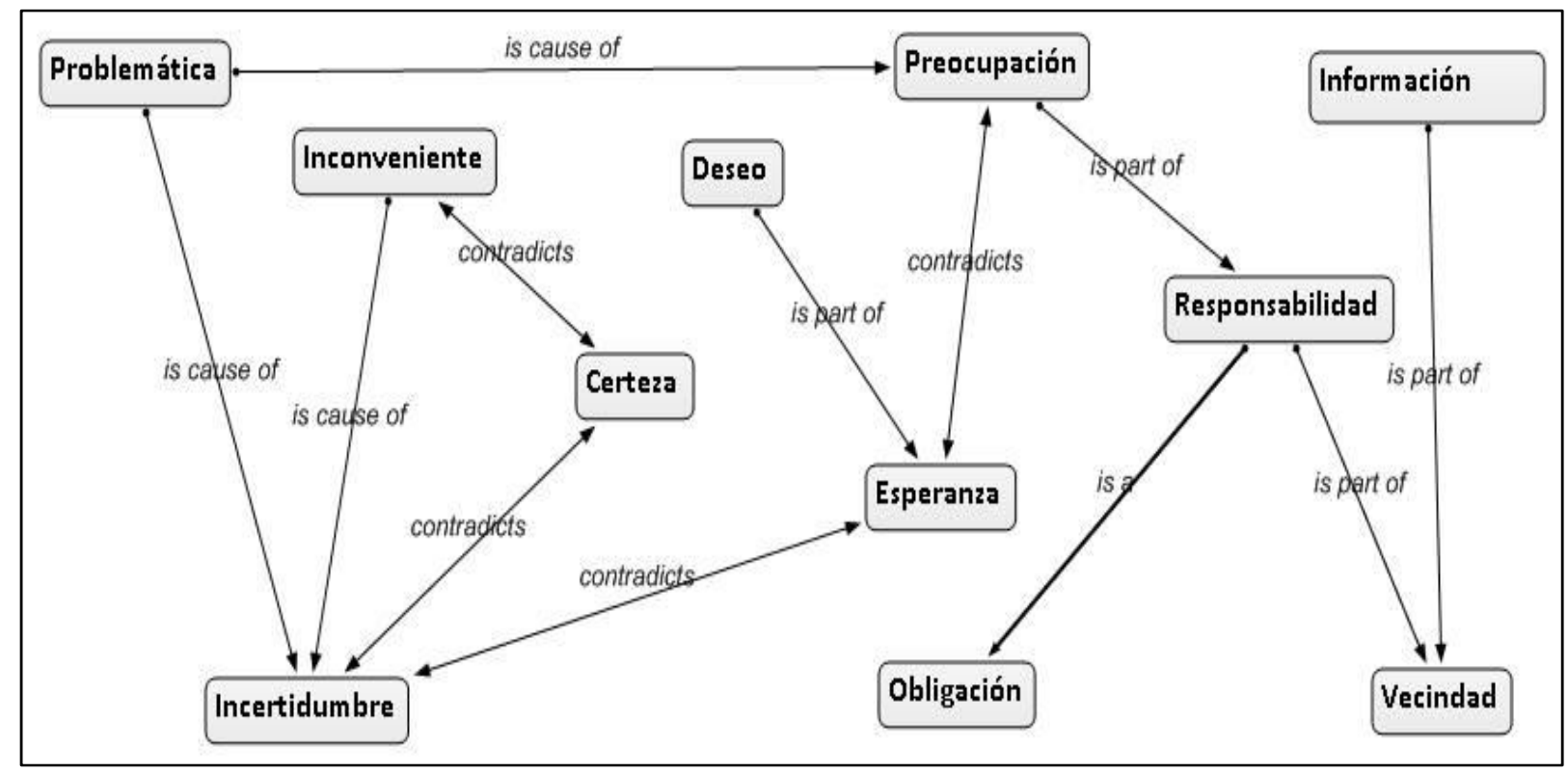

Figura 3. Familia socioeconómica. Fuente: Autores

Las estrategias de adaptación al cambio climático de la Federación y su adopción en el municipio de Acevedo: La Federación Nacional de Cafeteros [FNC], y el Centro Nacional de Investigaciones de Café [Cenicafé] han desarrollado una estrategia que permite brindar herramientas a los cafeteros a fin de que logren adaptarse a la variabilidad climática; esto con el objetivo de sostener la productividad y la competitividad del sector (FNC, 2012). En la estrategia se encuentran aspectos claves como:

- Siembra de variedades de café resistentes, como la Castilla, resistente a la roya, que, además, tiene una ventaja en productividad $17 \%$ mayor con respecto a las variedades Caturra y Colombia.

- Adecuado manejo de la densidad y arreglo espacial de los cafetales, complementados con un manejo agronómico apropiado y unas buenas prácticas de conservación de suelos.

- Renovación de cafetales, ya que se señala que las zonas cafeteras con plantas mayores a los nueve años deben renovarse con variedades resistentes y con la densidad adecuada.

- Manejo fitosanitario de los arbustos para controlar la roya y la broca; esto mediante periódicas fumigaciones y la realización del re-re, es decir, recoger todos los granos maduros, sobremaduros y secos, tanto del árbol como del suelo, tras la maduración del café.

- Manejo adecuado del sombrío, pues los ciclos de lluvias seguidos de largos periodos secos implican que el arbusto de café no podría sobrevivir a estos últimos sin la protección y la conservación de la humedad derivada de los árboles que cubren las plantaciones.
- Conservación de suelos por medio de las siembras a través de la pendiente, del manejo correcto de arvenses o malezas para que amortigüen los golpes de lluvia y de algunas prácticas que contrarresten la erosión.

A esto se suma la labor de investigación científica enfocada hacia el cambio climático realizada por Cenicafé, que mediante la agroclimatología hace seguimiento de la dinámica de los factores climáticos y las posibles soluciones. De igual manera, se investiga sobre fertilización, fisiología de las variedades y conservación de suelos. Esto con el objetivo de entregar recomendaciones específicas para cada región y ofrecer las herramientas de adaptación y mitigación de los efectos del cambio climático en el café.

Teniendo en cuenta lo anterior, en el trabajo de campo se identificó que a pesar de que la FNC ha establecido una estrategia de adaptación al cambio climático, esta no ha sido aceptada por los caficultores, quienes consideran que las medidas a implementar son poco rentables. Un ejemplo de esto es la renovación de cafetales, como lo mencionan los productores, quienes no la consideran una alternativa viable debido a que requiere de una alta inversión en semillas, insumos y mano de obra; adicionalmente, las áreas en renovación no estarán en producción, lo que significa la disminución de ingresos; además, se requiere de un manejo intensivo a lo largo del proceso, porque si las plántulas no retoñan, se habrá perdido la inversión.

En cuanto al manejo fitosanitario, la labor de control 
tanto de la roya como de la broca, que son las principales plagas que afectan al café, requiere de insumos químicos para su control y manejo, lo que representa altos costos de inversión para el productor. Cabe resaltar que además de los costos esta actividad implica afectaciones para la salud tanto del productor como de su familia, así como afectaciones edafológicas, y la FNC no ofrece alternativas diferentes al control químico, además del re-re, el cual demanda disponibilidad de tiempo para realizarse (Ascanio \& Carrascal, 2013).

En cuanto al hecho de que se debe aplicar un fertilizante adecuado en el momento oportuno para garantizar la nutrición del café, los productores lo ven como una tarea difícil de realizarya que la variabilidad del clima no permite llevar a cabo una fertilización adecuada. Por ejemplo, en largos periodos de sequía los fertilizantes serían dispersados por la acción del viento, lo cual significa, a su juicio, una pérdida de la inversión. Caso similar ocurre con el exceso de lluvia, ya que los nutrientes se perderían debido a los procesos de lixiviación y escorrentía, por lo que los productores deben optar por enterrarlo y esto acarrea más jornales de trabajo.

\section{Conclusiones}

Aunque a raíz de la problemática presentada en la producción de café en el país, la FNC y Cenicafé han creado una serie de estrategias de adaptación a la variabilidad climática, se evidencian falencias en términos de su conocimiento, aceptación y aplicación por parte de los productores. Estos consideran que las estrategias de adaptación son poco viables, pues asuntos como la renovación de cafetales y los controles químicos que están sugeridos en ella representan, por un lado, un periodo de tiempo improductivo y sin ingresos para las familias y por el otro, un incremento significativo en los costos de producción, lo cual hace que la rentabilidad del cultivo disminuya considerablemente y sea poco atractiva.

Teniendo en cuenta que la variabilidad del clima es un fenómeno difícil de manejar, se percibe una incertidumbre entre los productores acerca del futuro de sus cafetales; esta situación se podría remediar con la disponibilidad de información sobre los periodos críticos del clima y la mejora de los procesos de transferencia de tecnología por parte de las entidades afines al sector cafetero nacional.

\section{Agradecimientos}

Se agradece a los cultivadores de café del Municipio de Acevedo, Huila, por su constante acompañamiento y respaldo durante el proceso de investigación, en especial, al señor Otaín Herrera y su esposa, Mariela Bahamón, por su colaboración y disposición como principales referentes de la problemática expuesta.

\section{Referencias}

Alcaldía Municipal de Acevedo. (2012a). Plan de desarrollo municipal, 2012-2015. Recuperado de http://www.acevedo-huila.gov.co/apc-aa-fil es/33323164316666353236626534363433/PLAN_ DE_DESARROLLO_MUNICIPAL_TRABAJAMOS_DE_ CORAZON_POR_ACEVEDO_2012_2015.pdf

AlcaldíaMunicipaldeAcevedo.(2012b).Informedegestiónfinal, 2012-2015. Recuperado de http://acevedo-huila.gov.co/ apc-aa-files/38363731306361383361383336303531/ informe-de-gestion-final.pdf

Ariza, H. (2015). Revisitando estrategias de sostenibilidad de las empresas a través de una visión sistémica empresarial. I+D Revista de Investigaciones, 5(1), 2342. Recuperado de https://doi.org/10.33304/revinv. v05n1-2015002

Ascanio, G. \& Carrascal, P. (2013). Caracterización de la actividad económica empresarial de la ciudad de Ocaña. I+D Revista de Investigaciones, 2(2), 6-19. Recuperado de https://doi.org/10.33304/revinv. v02n2-2013001

Asociación Nacional de Café. (2013). La roya del café es una enfermedad temible, pero puede controlarse. Recuperado de https://www.anacafe.org/glifos/ index.php/Recomendaciones_Control_Roya

Barquero, M. (2013). Recomendaciones para el combate de la roya del cafeto ( $3^{\mathrm{a}}$.ed.). San José, Costa Rica: Instituto del Café.

Café de Colombia. (2014a). ¿Cómo impactan El Niño y La Niña la producción de Café de Colombia? Recuperado de http://www.cafedecolombia.com/bb-fnc-es/ index.php/comments/como_impactan_el_nino_y_ la_nina_la_produccion_de_cafe_de_colombia

Café de Colombia. (2014b). Café de Huila (DOP), uno de los más reconocidos orígenes de alta calidad. Recuperado de http://www.cafedecolombia.com/cci-fnc-es/ index.php/comments/cafe_de_huila_dop_uno_de_ los_mas_reconocidos_origenes_de_alta_calidad/

Calivá, J. (2013). Buenas prácticas de extensión para capacitar, organizar y transferir tecnologías a los productores de café. San José, Costa Rica: Instituto Interamericano de Cooperación para la Agricultura. Recuperado de http://repiica.iica.int/docs/b3360e/ b3360e.pdf

Camargo, M. (2010). The impact of climatic variability and climate change on arabic coffee crop in Brazil. Bragantia, 69 (1), 239-247. Campinas, Brazil.

Cano, C., Mejía, C., Caicedo, E., Amador, J. \& Tique, E. (2012). El mercado mundial del café y su impacto 
en Colombia. Recuperado de http://www.banrep. gov.co/sites/default/files/publicaciones/archivos/ be_710.pdf

Catalán, W. (2012). Asistencia técnica dirigida en manejo integrado de plagas en el cultivo de Café. Recuperado de http://www.agrobanco.com.pe/data/uploads/ ctecnica/011-I-cafe.pdf

Centro Nacional de Investigaciones de Café. (2009). Variabilidad climática en la zona cafetera colombiana asociada al evento de El Niño y su efecto en la caficultura. Recuperado de https://www.cenicafe. org/es/publications/avt0390.pdf

Centro de Estudios para el Desarrollo Rural Sustentable y la Soberanía Alimentaria. (2014). Producción y mercado de café en el mundo de México. Recuperado de http://www. cedrssa.gob.mx/post_n-produccinin_y_mercado_de_ cafn-n-_en_el_mundo_y_en_mn-xico.htm

Cermeli, M. (2016). Control químico de insectos plaga: Universidad Central de Venezuela. Recuperado de http://www.ucv.ve/fileadmin/user_upload/ facultad_agronomia/Zoologia_Agricola/Manejo_ Integrado/Competencia2/GUIA_CONTROL_ QUIMICO_FMIIP_2016.pdf

Charlotte, L., Jarvis, A. \& Ramirez, J. (2011). Agricultura colombiana: Adaptación al cambio climático. Cali: Centro Internacional de Agricultura Tropical. Recuperado de http://dapa.ciat.cgiar.org/wpcontent/uploads/2013/02/politica_sintesis 1 _ colombia_cambio_climatico.pdf

Coordinación Latinoamericana y del Caribe de Pequeños Productores de Comercio Justo. (2010). Importancia del pequeño productor y la agricultura sostenible para la conservación del ecosistema. Recuperado de http://clac-comerciojusto.org/wpcontent/uploads/2015/04/2010-Importancia-delpeque $\%$ C3\%B1o-productor.pdf

Coordinadora Latinoamericana y del Caribe de Pequeños Productores de Comercio Justo. (2015). Cambio climático: La voz de los pequeños productores. Recuperado de http://clac-comerciojusto.org/wpcontent/uploads/2015/05/Folleto-COP20.pdf

Corporación Colombiana de Investigación Agropecuaria. (2011). Informe técnico final. Proyecto de investigaciones sobre los efectos del cambio climático en la distribución altitudinal de insectos plaga del café y sus enemigos naturales en la zona cafetera de Colombia.

Cuadras, M. (2015). Café y medio ambiente: El Cambio Climático. Recuperado de http://www.forumdelcafe. com/pdf/F-49_Cambio_climatico.pdf

Dufour, P. (2008). Manejo integrado de la broca del café diseñado con tres componentes. Recuperado de http://agritrop.cirad.fr/544553/

Federación Nacional de Cafeteros de Colombia. (2009). El comportamiento de la industria cafetera colombiana durante 2009. Recuperado de http://www. federaciondecafeteros.org/static/files/Informe $\% 20$ de\%20la\%20Industria\%202009\%20internet.pdf

Federación Nacional de Cafeteros de Colombia. (2012). La caficultura, camino a convertirse en una actividad climáticamente inteligente. Recuperado de http:// www.cafedecolombia.com/cci-fnc-es/index.php/ comments/la_caficultura_camino_a_convertirse_ en_una_actividad_climaticamente_intelig/

Federación Nacional de Cafeteros de Colombia. (2013a). Comportamiento de la Industria Cafetera Colombiana 2013. Recuperado de https://www. federaciondecafeteros.org/static/files/Informe_ Industrial_2013_Web.pdf

Federación Nacional de Cafeteros de Colombia. (2013b). La caficultura colombiana y sus instituciones siguen trabajando con visión de futuro. Recuperado de http://www.federaciondecafeteros.org/particulares/ es/sala_de_prensa/detalle/la_caficultura_ colombiana_y_sus_instituciones_siguen_ trabajando_con_vision_/

Federación de Cafeteros de Colombia. (2017). Incremento de la producción nacional de café. Recuperado de https://www.federaciondecafeteros.org/clientes/es/ sala_de_prensa/detalle/produccion_de_cafe_de_ colombia_aumenta_12_en_enero/

Gobernación del Huila. (2015a). Información General del Departamento del Huila. Recuperado de http:// www.huila.gov.co/conoce-el-huila/informacion-deldepartamento.html

Gobernación del Huila. (2015b). Municipios del Huila. Recuperado de http://www.huila.gov.co/images/ stories/flash/municipios/flash.html

Grupo Intergubernamental de Expertos sobre el Cambio Climático. (2007). Cambio climático 2007. (Informe de síntesis). Recuperado de https://www.ipcc.ch/pdf/ assessment-report/ar4/syr/ar4_syr_sp.pdf

Gutiérrez, M. (2014). Curso: Investigación cualitativa aplicada a la Ciencia Política. Bogotá: Universidad Javeriana. Recuperado de http://www.javeriana.edu. co/blogs/mlgutierrez/files/Enfoques-y-estrategiasde-investigacion4.pdf

Infocafé. (2015). Principales productores de café del mundo. Recuperado de http://www.infocafe.es/cafe/ principales-productores-cafe.php

Jaramillo, A. \& Arcila, J. (2009). Variabilidad climática en la zona cafetera colombiana asociada al evento de La Niña y su efecto en la caficultura. Avances Técnicos Cenicafé. Recuperado de http://www.cenicafe.org/ es/publications/avt0389.pdf

Laderach, P., Jarvis, A., Ramírez, J., Eitzinger, A. \& Ovalle, O. (2009). The implications of climate change on mesoamerican agriculture and small-farmers coffee 
livelihoods. Hamburgo, Alemania: Tropentag. Recuperado de http://www.tropentag.de/2009/ abstracts/full/367.pdf

Ortiz, R. (2012). El cambio climático y la producción agrícola. Recuperado de http://idbdocs.iadb.org/ wsdocs/getdocument.aspx?docnum $=36736182$

Patiño, M., Pencue, E. \& Vargas, R. (2016). Determinación del contenido de humedad en granos de café pergamino seco utilizando speckle dinámico. Revista Biotecnología en el Sector Agropecuario y Agroindustrial, 14 (2), 84-91.

Portafolio. (2015a). Cafeteros toman medidas para aliviar efectos de El Niño. Recuperado de http://www. portafolio.co/economia/finanzas/cafeteros-tomanmedidas-aliviar-efectos-nino-34286

Ramírez, J. (2014). Planeación por escenarios: una opción para el sector cafetero. Revista Estrategia. Recuperado de http://www.urosario.edu.co/Mision-Cafetera/ Archivos/INFORME-DE-CONSULTORIA-CAFE-JRV.pdf

Sánchez, V., Rincón, A., Toledo, V. \& Gómez, A. (2016). Caracterización del papel de la mujer en el proceso de polinización manual en el cultivo de maracuyá (Passiflora edulis). Revista Uninpahu investigaciones, 25(12), 107-117.

Zapata, P. (2015). Impacto climático sobre el café colombiano: Universidad de Ciencias Aplicadas y ambientales. Recuperado de https://www.dinero. com/economia/articulo/consecuencias-climaticassobre-cafe-colombiano/207404 